\title{
TIEMPO Y ESPACIO EN EL CRUCE ENTRE FILOSOFÍA Y MÚSICA EN EL PENSAMIENTO DE THEODOR W. ADORNO EN LA DÉCADA DE 1960
}

\author{
Marina Hervás MuÑoz \\ Universidad Autónoma de Barcelona \\ bttp://dx.doi.org/10.15304/ag.38.2.5062
}

\section{Resumen}

Este texto analiza la importancia del espacio y el tiempo en la filosofía de Theodor W. Adorno en sus últimos textos (algunos aún sin publicar). Primero se traza el giro que dio su pensamiento a partir de 1957, debido a la crítica de H-K. Metzger. Adorno no solo revisa a partir de ella su postura en aspectos musicológicos, sino que la música le lleva a reflexionar sobre la relación dialéctica entre lo estático y lo dinámico, cómo se articula la tensión entre lo sonoro y la imagen y cómo ambos elementos inciden en una configuración del tiempo no representativa, es decir, no reducida a la narrativa lineal. Esto le permite repensar la causalidad y, también, las metáforas visuales comúnmente utilizadas en la comprensión del tiempo. Esto es clave para comprender, entre otras cosas, su crítica a la búsqueda de invariantes o la pregunta por la Ungegenständlichkeit en su Negative Dialektik.

Palabras clave: Adorno, música, filosofia, espacio, tiempo.

\section{Abstract}

This text analyzes the importance of space and time in Th. W. Adorno's philosophy in his late writings (some of them remain unpublished). First, it is delineated the shift that Adorno's thought experienced from 1957, due to the H-K. Metzger's criticism. Adorno not only reviews his posture in musicological aspects, but music leads him to reflect on the dialectical relationship between the static and the dynamic, how the tension between the sound and the image is articulated and, above all, how both elements affect a non-representative time configuration, that is, not reduced to a linear narrative. The causality and also the visual

Recibido: 12/04/2018. Aceptado: 29/05/2018. 
metaphors commonly used in the understanding of time are thus reconsidered. This seems to be crucial to understand among other things, his criticism of the search for invariants or the issue of the Ungegenständlichkeit in his Negative Dialektik.

Keywords: Adorno, music, philosophy, space, time.

\section{Introducción. Un gesto de humildad intelectual}

Este trabajo parte de la asunción de que la música, en la filosofía de Theodor W. Adorno, no es un objeto más entre sus ocupaciones, sino que fue motor para su pensamiento. Y, además, como mostraré enseguida, parece que Adorno revisó algunas de sus posturas más arraigadas al respecto en sus últimos años, es decir, en la década de 1960 y que tal giro influyó poderosamente en su modelo teórico para el eje espacio-tiempo y estáticodinámico, fundamentales en su teoría del conocimiento y proyecto de la dialéctica negativa. En los últimos diez años de su vida, Adorno comenzó a escuchar una música que no había oído antes, lo que hizo plantearse algunas cuestiones que más o menos había venido trabajando de una forma similar a lo largo de su proyecto filosófico. Sus dudas vienen cuando por primera vez, como señala en Vers une musique informelle (1961), "no era capaz de participar como oyente en la composición".

Adorno estuvo en los Cursos Internacionales de composición de Darmstadt desde que volvió del exilio. Desde 1950 y hasta 1956 se ocupó, fundamentalmente, de la recepción de Schönberg —en parte gracias a Rene Leibowitz - y a la cuestión de la reproducción musical, un tema sobre el que escribió desde su juventud, en especial junto a a Kolisch y Steuermann ${ }^{1}$. El cambio comienza en 1957, cuando recibe una dura crítica del joven musicólogo Heinz Klaus Metzger, que analizaremos enseguida. Hasta 1960, la recepción de los textos de Adorno es doble: aunque es muy leído y respetado, también se extiende la objeción de Metzger de que no sólo ha envejecido la Philosophie der neuen Musik, pues parece ya no es capaz de dar cuenta de los problemas contemporáneos en composición, sino también su escritor. En 1961 Adorno "rejuvenece" con su Vers une musique informelle, texto al que le sigue en 1965 «Form in der neuen Musik» (¡dedicado a Boulez!) y en 1966 «Funktion der Farbe in der Musik», dos textos totalmente novedosos en su producción y que se cruzan muy significativamente con su proyecto de

${ }^{1}$ Como puede apreciarse en las lecciones recogidas en las recientemente publicadas en T. W. Adorno, Kranichsteiner Vorlesungen, en Nachgelassene Schriften IV, 17, Berlin, Suhrkamp, 2014. Sobre la reproducción musical se ocupó en T. W. Adorno, Zu einer Theorie der musikalischen Reproduktion, Frankfurt a. M., Suhrkamp, 2005. 
la Negative Dialektik (aunque los detalles de este asunto exceden los límites de este trabajo).

La polémica entre Heinz-Klaus Metzger (desaparecido en 2009) y Adorno es una de las más recurrentes por parte de los detractores del filósofo de Frankfurt. En febrero de 1957, Metzger escribió un texto que unía dos textos adornianos de gran repercusión, a saber, Philosophie der neuen Musik y el del artículo «Das Altern der neuen Musik» (1954), adquiriendo el nombre de «El envejecimiento de la filosofía de la nueva música $»^{2}$. La crítica de Metzger, dicho con E. Campbell, puso «a prueba la tendencia de Adorno a generalizar, su menosprecio a las diferencias significativas en el acercamiento individual a los compositores y su fracaso al nombrar un solo ejemplo musical que le sirviera como evidencia» ${ }^{3}$. En concreto, además, Metzger critica la idea adorniana del "material" y de "progreso del material", la utilización de conceptos como "Vorder-" y "Nachsatz" (es decir, antecedente y consecuente) $)^{4}$, a la poca atención que Adorno prestó a la realización sonora [klangiche Realisation] y su concentración en la "música en papel" [Papiermusik] —es decir, su fijación en la partitura-, la inexistente mención al cambio en la consideración del tiempo en música, no sólo por la importancia del ritmo por encima — quizá- de lo armónico y lo melódico, sino también por la relación con lo espacial, es decir, donde la composición deviene "articulación del tiempo" (Metzger cita, para ello, por ejemplo,

${ }^{2}$ El texto se publicó en H-K. Metzger, «Das Altern der Philosophie der neuen Musik», en Die Reihe, vol. 4, 1958, aunque Adorno conocía el texto desde 1957 y ambos discutieron por correspondencia al respecto durante todo este año. La correspondencia puede encontrarse en el Archivo de Adorno de Franfurt bajo la signatura TWAA Br 1005.

${ }^{3}$ E. Campbell, Boulez, Music and Philosophy. Cambridge, Cambridge University Press, 2010, p. 76. (A menos que se indique lo contrario, todas las citas son traducidas por mí).

${ }^{4}$ Stockhausen también fue crítico con este aspecto. Para él, el problema de Adorno es que "buscaba un perro en un cuadro abstracto" al seguir tratando de encontrar "Vorder" y "Nachsatz" (Véase G. Kreis, «Kritik der avantgardistischen Vernunft. Kants Grundlegung des Kunstwers und Adornos Kriterien der neuen Musik», en R. Klein (ed), Gesellschaft im Werk. Musikphilosophie nach Adorno, Friburgo, Karl Alber, 2015, p. 173). El debate al respecto surgió con motivo de la interpretación de la Sonata para dos pianos n. 1 de K. Goeyvaerts, un alumno de Messiaen, que Adorno criticó señalando que era una sonata que estaba "hecha", pero no "compuesta" (Cfr. M. Schwarz, "Editorische Nachbemerkungen" en T. W. Adorno, Kranichsteiner Vorlesungen, en Nachgelassene Schriften IV, 17, Berlin, Suhrkamp, p. 641) y le pidió que le explicara dónde se encontraban la "Vorder-" y la "Nachsatz" y la construcción motívica, "categorías que aún se exigían absolutamente en Schönberg», y que ya no tenían que ver con los principios constructivos de Goeyvaerts, interesado en como "cada tono adquiría su significado en la totalidad de la fuga». G. Borio y H. Danuser, Im Zenit der Moderne. Die Internationalen Ferienkurse für neuen Musik Darmstadt 1946-1966, Volumen I. Freiburg im Breisgau: Rombach, 1997, p. 300. 
Four systems o For David Tudor, 1952 de E. Brown). Asimismo, Metzger se basa en un argumento contrafáctico, en tanto señala que Adorno no hubiese opinado algunas cosas si, según su criterio, hubiese escuchado obras fundamentales de la electrónica como el Octet I for 9 loudspeakers (1953) de Brown, Klangfiguren (1954-1964) de Koenig y Gesang der Jüngliche (1955-56), de Stockhausen.

La respuesta de Adorno a tal crítica, en lugar de llegar en el volumen de Die Reihe siguiente al que incluyó el texto de Metzger, como originalmente estaba planeado, adoptó la forma de clase magistral, concentrando así su intervención de ese año de Darmstadt en responder a Metzger: así surge «Criterios de la nueva música» (1957). Ahí, por ejemplo, aclara la cuestión de la utilización de los conceptos de "Vorder-" y "Nachsatz". Considera que es una crítica injusta, ya que él lo planteaba como categorías del lenguaje musical tradicional que habría que repensar al mismo tiempo que se repensaba la tonalidad, ya que tal relación entre antecedente y consecuente coincidía, por ejemplo, con la de dominante y tónica ${ }^{5}$. Para él, y en eso proponía concentrarse, ambos conceptos remitían a una preocupación mayor: a la relación de las partes con el todo y viceversa ${ }^{6}$. No obstante, en su conferencia «Zum Problem der musikalischen Analyse» ${ }^{7}$, dictada en 1969, Adorno muestra signos de haberse hecho cargo de la crítica de Metzger cuando señala que la nueva música (hablando de Alban Berg) requiere algo diferente al análisis motívico-temático habitual ${ }^{8}$. En cuanto a la poca atención que Adorno prestó a la 'klangiche Realisation' y su concentración en la 'Papiermusik', Adorno encuentra esta propuesta estimulante, pero reconoce su anclaje, al menos en la preparación previa a la escucha, a la partitura ${ }^{9}$. Entre otras cosas, Adorno se defendió diciendo que no tuvo acceso a las obras que Metzger le sugería ${ }^{10}$. Metzger, por su parte, escribió cómo, en realidad,

${ }^{5}$ T. W. Adorno, Gesammelte Werke, Volumen 16, Frankfurt a. M., Suhrkamp, 1976, p. 173.

${ }^{6}$ Cfr. Carta de Adorno a Metzger del 26 de abril de 1957, Br 1005/26. (La signatura genérica "Br" se refiere a "cartas" según el registro del Archivo de Adorno de Frankfurt a. M.)

${ }^{7}$ T. W. Adorno, Frankfurter Adorno Blätter VII, Múnich, Text+Kritik, 1992, pp. 73-89.

8 Pese a esta petición, aún no la había practicado realmente en relación a otros compositores ni lo veremos realmente en sus análisis.

${ }^{9}$ Carta de Adorno a Metzger, Br 1005/38, del 5 de julio de 1957. En este aspecto vemos un punto polémico en Adorno, ya que su postura el 1954, en «Das Altern der neuen Musik» era crítica con las partituras de la nueva música. Dice explícitamente que "aparte de partituras de un aspecto lo más complicado imaginable, no sucede nada más» (T. W. Adorno, Gesammelte Werke, Volumen 14, Frankfurt a. M., Suhrkamp, 1976, p. 151).

10 "Er habe in Unkenntnis dieser Quellen [es decir, obras de Boulez, Stockhausen, Koenig, Brown y Nilsson] seine Arbeit geschrieben , unter der Behauptung in Schutz, zur 
podría haberse agenciado algunos documentos y haber asistido al estreno de algunas obras que se publicaron y estrenaron antes de la publicación de Dissonanzen, donde se encuentra el texto «Das Altern der neuen Musik» ${ }^{11}$. Aunque esto sea verdad y no sean relevante en exceso los datos biográficos que impidieron a Adorno asistir a tales estrenos o conseguir esos vinilos, libros y partituras ${ }^{12}$, en la correspondencia con Metzger le pide referencias e información para conseguir más materiales y le pide expresamente que se los mande de Francia. Además, Adorno le pidió a Metzger consejo sobre música que él consideraba fundamental conocer para entender aquellos años $^{13}$. No cabe aquí detenernos en todos los detalles de esta polémica, pero sí remarcar que parece que ésta puso a Adorno, como sospechamos, en la línea de un cambio, que tendría su primera expresión fundamental en su texto de 1961 "Vers une musique informelle» ${ }^{14}$.

En enero de 1966 se publicaba una reedición de su libro (y tesis de habilitación) Kierkegaard. Konstruktion des Ästhetichen ${ }^{15}$, escrito originalmente en 1929-1930. En la "Noticia", Adorno indica algo que se puede extrapolar al ámbito de sus escritos sobre música: "desde muy temprano (el autor) ha sentido desconfianza hacia quienes reniegan de sus trabajos de juventud (...). Uno debe hacer lo que buenamente pueda en cada época, pero luego dejar lo hecho como está (...). Lo que de una producción tiene posibilidad de durar y lo que no, escapa a la opinión y voluntad de su autor ${ }^{16}$. Por eso, parece importante señalar que los cambios que indicaremos a continuación que parece que se observan en la filosofía de la música de Adorno no son, en ningún caso, radicales, no son una "nueva vida" de manera explícita, aunque sí que parece que dan herramientas nuevas con las que afrontar la nueva música también después de Adorno. Lo que parece evidente es que Adorno, al menos, piensa muy seriamente los años anteriores a Darmstadt

Zeit der redaction seines Textes seien sie vorwiegend noch unzugänglich gewesen». Cfr. H-K. Metzger, Literature zu Noten. Frankfurt a.M., Suhrkamp, 1980, p. 108.

${ }^{11}$ Ibidem, p. 109.

12 Él mismo señaló lo difícil que era conseguir vinilos en la Alemania de mitad de la década de los 50 en una carta al propio Metzger, el 16 de agosto de 1957.

${ }^{13}$ Cfr. La carta del 26 de junio de 1957 (Br 1005/26) y la respuesta de Metzger el 2 de julio del mismo año. Metzger le recomienda numerosas obras de Stockhausen y Koenig, la Polyphonie X, Le marteau sans Maître y Le Visage nuptial de Boulez, el Quintette à la Mémorie de Webern de Pousseur, Schlagfiguren de Bo Nilssons, Music of changes de Cage, y Octet for 8 loudspeakers y 25 Pages de Brown.

${ }^{14}$ T. W. Adorno, Gesammelte Werke, Volumen 16, Frankfurt a. M., Suhrkamp, 1976.

${ }^{15}$ Hoy en T. W. Adorno, Gesammelte Werke, Volumen 2, Frankfurt a. M., Suhrkamp, 1976.

${ }^{16}$ Ibidem, p. 261. 
desde un foco diferente. Asimismo, en una carta a Metzger en 1957, Adorno reconocía que:

si hoy escribiera la Philosophie der neuen Musik lo haría de una forma distinta a como lo hice hace diecisiete y nueve años, aunque no sé si la escribiría en general, si me resistiría a hacerlo, ya que comprendo su complejidad de una forma totalmente distinta a entonces ${ }^{17}$.

Es decir, Adorno era consciente, como Metzger dijo en su artículo, del "envejecimiento" de la Filosofía de la nueva música y reconoció, a partir de entonces, en muchísimas cartas y conferencias su entusiasmo por autores como Stockhausen, Ligeti o Boulez. Este entusiasmo no resulta interesante sólo a nivel biográfico, sino también porque sugiere un cambio que Adorno se dirigía a tomar en su modelo teórico cuando le alcanzó la muerte. Aquí no se va a defender que Adorno anticipó —o algo por el estilo- algunos de los problemas que hoy operan en la filosofía de la música, sino ver cómo ya en Adorno se abrieron las preguntas iniciales del camino que se tomó a partir de los cursos de Darmstadt. A diferencia de la conocida critica de H-K. Metzger que, según W. Philips, concretiza que "Adorno no estaba preparado para escuchar la nueva generación" 18 , considero que Adorno no tuvo tiempo para redirigir su trabajo pero sí que realizó importantes esfuerzo para pensar seriamente "lo que ya no entendía" de la música contemporánea. Lo más cercano que tenemos al dibujo de ese cambio se encuentra en el texto "Vers une musique informelle" y en textos no publicados.

17 "[W]enn ich heute die Philosophie der neuen Musik schreibe, könnte ich sie ganz anders schreiben als von siebzehn und dann vor neun Jahren; obwohl ich dann wieder nicht weiß, ob ich sie heute überhaupt schreiben könnte, und ob mich nich gerade hemmen würde, dass ich die Komplexität ganz anders übersehe als damals». Carta de Adorno a Metzger del $\mathrm{Br}$ 1005/18, del 28 de febrero de 1957. Del año 1957 es, precisamente, el texto que dio lugar a la disputa pública entre Metzger y Adorno, a saber, "Das Altern der Philosophie der neuen Musik», publicado hoy en H-M. Metzger Literatur zu Noten, Frankfurt a.M., Suhrkamp, 19801980, pp. 61-89. Soy consciente de que en «Stravinsky. Ein dialektisches Bild», Adorno señala que "nada encuentro de lo que retractarme en lo escrito en 1947" pero, añade, "no poco que ampliar en autorreflexión crítica" (T. W. Adorno, Gesammelte Werke, Volumen 16, Frankfurt a. M., Suhrkamp, 1976, p. 383). También, aunque haya señalado que Philosophie der neuen Musik «fue determinante para todo lo que escribí después sobre música» (T. W. Adorno, Gesammelte Werke, Volumen 10.2, Frankfurt a. M., Suhrkamp, 1976, 719), creo que tiene más que ver con un asunto temático que con un mantenimiento de los argumentos, pues los propios textos hablan de la divergencia (por no decir que, como el mismo Adorno sabía, la intención y lo conseguido no siempre confluyen). Adorno era consciente de los cambios del pensamiento, por eso respeta los suyos propios. El gesto de no retractarse tiene más que ver con eso que con un mantenimiento literal y sin fisuras de sus planteamientos anteriores.

${ }^{18}$ W. Philips, Metaphysics and Music in Adorno and Heidegger, Nueva York, Palgrave Macmillan, 2015, p. 104. 


\section{Orígenes teóricos del problema: Sobre estática y dinámica}

Hasta la década de 1960, la crítica a lo estático había sido uno de los núcleos de la crítica adorniana a la prima philosophia. Para él, lo dinámico, lo cambiante, lo temporal, había sido clasificado como meros "accidentes" de lo estático, lo invariable, lo eterno. La búsqueda de un momento fundante se refiere a lo inmutable, a lo invariable, es decir, a lo que no tiene tiempo. Por eso, para Adorno, la dialéctica tendría por principio poner en cuestión la continuidad y discontinuidad, así como mostrar la dinámica interna de las categorías congeladas y pensar desde la complejidad de lo temporal conceptos que parece que rehuían por definición de la temporalidad como la verdad. En su madurez, Adorno es también crítico con lo mero dinámico, pues solo puede haber algo cambiante si hay algo que permanece. Lo estático se había clasificado como el "orden" y lo dinámico como el "progreso", de tal modo que el progreso siempre llevaba al orden, a un punto estático final como meta.

Las categorías de lo estático y lo dinámico adquieren una importancia fundamental en la última década de producción adorniana a la luz de un texto de 1961 (el mismo año que "Vers une musique informelle») «Über Statik und Dynamik als soziologische Kategorien» ${ }^{19}$, donde Adorno teoriza por primera vez la tensión que lo estático le presenta a lo dinámico. Hasta este momento, la revisión de Adorno de la tradición se centraba en la crítica a su tendencia hacia lo estático, como se ha señalado, hacia la búsqueda y fijación de invariantes (lo estático) e indicaba el carácter histórico de tales invariantes, lo cual las convertía en dinámicas, en estos años Adorno tematiza de forma explícita que la dinámica «se convierte a sí misma en lo siempre igual, en estática ${ }^{20}$. Parece que, de este modo, Adorno condena el modelo temporal subyacente en el pensamiento hegeliano y el marxista, en la medida en que la dinamización es, en realidad, una caída en un modelo de dinámica que «devora todo lo demás de forma obstinada, persiguiendo obsesivamente lo único» ${ }^{21}$. En el caso hegeliano, se trata del autoconocimiento del espíritu. En el marxista, la sociedad sin clases. No hay «aceptación redentora de lo otro, que hasta ahora se limitó a verse oprimido y, donde fue posible, exterminado ${ }^{22}$. Lo que propone Adorno, tal y como

19 T. W. Adorno, Gesammelte Werke, Volumen 8, Frankfurt a. M., Suhrkamp, 1976, pp. 217-238.

${ }^{20}$ T. W. Adorno, Gesammelte Werke, Volumen 8, Frankfurt a. M., Suhrkamp, 1976, p. 235.

${ }^{21}$ Ibidem.

${ }^{22}$ Ibidem. 
se desarrollará a continuación, es pensar la tensión entre lo estático y lo dinámico en términos de espacio y tiempo. Su objetivo es reflexionar ambas categorías de tal forma que la estática no quede reducida a lo invariante ni a contrapunto de la dinámica y viceversa.

\section{De la tensión estática-dinámica al tiempo-espacio}

El tiempo es fundamental en la filosofía adorniana pues uno de sus ejercicios fundamentales es "poner en movimiento" las categorías filosofías. La conceptualización del tiempo que había trabajado hasta la década de los 50 era la que dividía el tiempo en tres: el tiempo "vacío", el tiempo "extensivo" y el tiempo "intensivo". Adorno resume estos dos momentos en Philosophie der neuen Musik: el tiempo intensivo sería la "miniatura expresiva de la escuela de Viena" que "contrae la dimensión temporal, como dice Schönberg, al "expresar una novela con un único gesto" " ${ }^{23}$, La similitud entre el tiempo intensivo y el concepto de imagen no es arbitraria. El tiempo extensivo, por su parte, aparecería en las grandes construcciones dodecafónicas, así como en el sinfonismo beethoveniano y mahleriano, al menos), donde «el tiempo se detiene en virtud de un procedimiento integral que [...] parece privado de evolución porque fuera de sí mismo no tolera nada sobre lo que pudiera probarse la evolución ${ }^{24}$. En realidad, tal y como apunta en sus Lecciones de estética de 1958-1959, aunque sea un ideal, lo que el arte pide, en realidad, es pasar de lo extensivo a lo intensivo, es decir "captar el todo en un solo instante", o lo que él considera que puede llegar a ser la "captación inmediata de algo mediado" 25 .

${ }^{23}$ T. W. Adorno, Gesammelte Werke, Volumen 12, Frankfurt a. M., Suhrkamp, 1976, p. 177.

${ }^{24}$ Soy consciente de que, a primera vista, esto podría ser problemático. Parece que en ambos tipos de tiempo, según esta frase, el tiempo se detiene. Bien, la diferencia fundamental se encuentra en que el tiempo extensivo incluye la variación en la forma, es decir, que extiende sus límites hasta llegar a momentos en que parece que no pasa nada porque el tiempo queda suspendido. Cuando habla de que "no tolera nada de lo que no pudiera probarse su evolución", se refiere, específicamente, a la inmanencia formal del movimiento. A diferencia de la música anterior, no permite que se introduzca nada que vuelva a "poner en movimiento" la suspensión, el autocontemplarse, la detención de la narración por parte del narrador, del aedo. La música continúa porque ha de continuar, y no porque la forma preestablecida se lo exija, como pasa, por el ejemplo, en los tradicionales rondós. Por otro lado, el tiempo intensivo opera con la detención en la medida en que la variación, el movimiento, se incluye en el fragmento, en lo mínimo, en el propio tema, que se disuelve por ese mismo movimiento inmanente, primero de forma atómica y luego en lo amorfo.

${ }^{25}$ Como Boissière sugiere, Adorno identifica el tiempo intensivo con la "contracción del tiempo" [contraction $d u$ temps] y no, a diferencia de Paul Bekker, en una "concentración de 
Uno de los lugares de desplazamiento en los últimos años de Adorno se encuentra en la exploración de las consecuencias de la unión entre el tiempo extensivo y el intensivo que, era la forma en la que caracterizaba la construcción del tiempo en la 'nueva música'; a su espacialización (algo que analiza desde el concepto de imagen). De este modo, vemos cómo el tiempo comienza a ser, definitivamente, una de las preguntas esenciales a partir en los años 60, desplazando la centralidad de la "Sprachähnlichkeit" ${ }^{26}$. Es decir, Adorno traslada su modelo lingüístico hacia el problema de la imagen en tensión con lo sonoro.

En lo musical, al igual que en modelos filosóficos tradicionales, para Adorno, el tiempo, lo dinámico, se transforma de forma paradójica en lo estático. Sin embargo, en lugar de condenarlo, modifica el concepto de imagen que desarrolló entre los años 30 y 50, marcado por la tensión con lo dinámico, por una defensa de la fuerza de lo estático. De ahí que defienda que "experimentar el arte significa captar su proceso inmanente en el instante de su detención", y no la cifra de lo desaparecido, de lo ya no-presente (como por ejemplo en Ernst Bloch). El salto que se da es la consideración de que la imagen es a la vez "estática y dinámica”, y no solamente estática y, además, negación de lo dinámico. Esto es fundamental en general para comprender una lectura algo coja que se ha hecho del concepto de espacialización, trabajado por varios comentadores como si Adorno se hubiera mantenido en la misma posición desde su Versuch über Wagner y Philosophie der neuen Musik ${ }^{27}$. Lo que está de fondo, como apunta A. Wellmer, es «el abandono

ideas" [concentration des idées]. (A. Boissière, La pensée musicale de T.W. Adorno : l'épique et le temps, Paris, Printemps, 2010, p. 55).

${ }^{26}$ Borio señala que esta "musiksprachlichen Artikulation" pierde su relación con la lógica del lenguaje y que habría que entenderla plenamente como "Stimmigkeit", coherencia. Véase G. Borio, «Die Positionen Adornos zur musikalischen Avantgarde zwischen 1954 und 166», en B. Sonntag, (ed), Adorno in seinen musikalischen Schriften, Regensburg: Gustav Bosse, 1987, p. 167. Uno de los abanderados en contra de la Sprachähnlichkeit fue D. Schnebel, que en un texto - que generó una gran polémica- de 1990 planteaba que el concepto de "Sprachählichkeit" no solo reducía el ámbito de reflexión sobre la constitución de la música, sino que además no daba cuenta de la paulatina tendencia a la "Versprachlichung" de la música a partir de 1970. Cfr. D. Schnebel, «Der Ton macht die Musik oder: Wider die Versprachlichung», en Anschlage-Auslage. Texte zur neuen Musik, Munich-Viena, Hanser, 1993.

${ }^{27}$ Me refiero a T. W. Adorno, Gesammelte Werke, Volumen 13 y 12, Frankfurt a. M., Suhrkamp, 1976. Ésa es la interpretación, por ejemplo, de S. Bidon-Chanal, «Música envejecida y retorno a la libertad. Las críticas a la Escuela de Darmstadt de T. W. Adorno y su propuesta de una "musique informelle" en Cadernos de Filosoia Alemã, 20; n. 2, pp. 201-217. 
paulatino de la temporalidad finalista-dirigida de la música, que era el paradigma del proceso motívico-temático del Beethoven medio» ${ }^{28}-\mathrm{y}$ por ende, de todo el marco tardoclásico y romántico-.

Esto sucede a partir, por ejemplo, de su análisis de las Drei Orchesterstücke Op. 6 de Alban Berg. Sin decirlo de forma explícita, Adorno valora a partir de esta obra "la desaparición del pensamiento armónico" (característico aún de Schönberg) que permite que «el color y el contrapunto se vuelv[a]n productivos». Esto implica, y ahí encontramos la primera filiación con lo informal, que «la forma la crean ellos mismos» ${ }^{29}$. Es decir, la forma ya no es algo "puesto desde arriba que se le impone al objeto, sino que surge del propio objeto (algo que caracteriza su teoría del lenguaje, en la que el concepto debería ser capaz de «atrapar en conceptos lo carente de conceptos sin reducirlo a ellos» $\left.{ }^{30}\right)$. Lo que me interesa remarcar es que, para Adorno, la composición ya no es meramente temporal: aparece la pregunta por el espacio. Si la forma -entendida como espacialización de lo sonoro (lo temporal) - es productiva por sí misma, ya no es meramente una "congelación", una conversión en "estático" de lo dinámico que sería lo sonoro, sino que contendría en su núcleo un principio dialéctico que la hace a la vez estática y dinámica.

Tres autores, al menos, permiten a Adorno modificar el centro de sus reflexiones sobre música: Berg, Debussy y Ligeti. Debussy, como demuestran los documentos en el archivo de Adorno de Frankfurt a. M. fue una de las referencias fundamentales de los últimos años de Adorno y donde claramente se ve su distancia con Philosophie der neuen Musik. Aunque solo conservan anotaciones sobre el compositor francés, son suficientes, si las utilizamos arqueológicamente junto a otros textos, para descubrir la importancia que adquiere el concepto de sonido comprendido desde el co$\operatorname{lor}^{31}$. Es especialmente relevante pues es en su música desde la que trabaja más acusadamente una nueva relación entre lo estático y lo dinámico, dada la relación de la música de Debussy con principios pictóricos ${ }^{32}$.Debussy, en

28 «Der zuhnemenden Abkehr von einer finalischtisch-gerichteten Zeitlichkeit der Musik, deren Paradigma das motivisch-tematische Verfahren des mittleren Beethoven war». A.Wellmer, Versuch über Musik und Sprache, München, Carl Hanser, 2009, p. 314.

${ }^{29}$ T. W. Adorno, Gesammelte Werke, Volumen 14, Frankfurt a. M., Suhrkamp, 1976, p. 414.

${ }^{30}$ T. W. Adorno, Gesammelte Werke, Volumen 6, Frankfurt a. M., Suhrkamp, 1976, p. 21.

31 Algo que se evidencia en las últimas lecciones que dictó en Darmstadt en 1966 «Funktion der Farbe in der Musik», que se encuentra en T. W. Adorno, Kranichsteiner Vorlesungen, Berlin, Surhkamp, 2014, pp. 447-540.

${ }^{32} \mathrm{Vt}$ 205, "Debussy", del 28 de febrero de 1963. ("Vt" es la asignatura genérica para "conferencias" del Archivo Theodor W. Adorno de Frankfurt a. M.). 
Philosophie der neuen Musik era todavía comprendido como un compositor "sin desarrollo" o, al menos, con un trabajo pobre del desarrollo. Mientras que ya reconoce que en Debussy ya no opera la "congestión y la distensión", es decir, el manejo de las tensiones y que hay una "yuxtaposición de colores y superficies", no encuentra en ello la fuerza de lo dinámico, sino que lo considera meramente estático, algo que posteriormente criticará, sobre todo en Stravinsky, como la mecanización de la composición y la "pseudomorfosis de la música en pintura". Lo estático, para el Adorno de antes de los años 60, era idéntico a la "disociación del tiempo" y la ruptura con el "decurso musical en el tiempo". Según él, la renuncia a lo temporal implicaba la eliminación de la trascendencia, la detención en el "mero-ahí". Su trabajo incompleto de Debussy hubiese consistido, por tanto, en un giro del carácter peyorativo de su lectura en Philosophie der neuen Musik ${ }^{33}$.

La pérdida de lo fijo [Fest] impide lo dinámico, pues sólo como contrastante con lo dijo puede desplegarse lo dinámico. La paradoja es formulada desde la asunción de que «la dinámica... [s] i se absolutiza, se detiene» ${ }^{34}$. Es decir, la radicalización de lo dinámico, que había sido lo característico hasta entonces, para él, en su concepción de la nueva música (de la Segunda Escuela de Viena) y marca, además, de elementos como el "desarrollo variativo" [Variative Durchführung] deriva en su contrario, en lo estático. Esto lo constata en el monodrama Erwartung, donde la tendencia hacia la renunciar de lo motívico-temático, a la absoluta variación, puede llevar a la "monotonía del cambio" 35 . Adorno se da cuenta de que para los compositores

${ }^{33}$ Cabría pensar si esto no implicaría también revisar el texto canónico de Paddison sobre la estética musical de Adorno, el cual se queda en la interpretación de Debussy de Philosophie der neuen Musik y traza desde ahí la relación con Mahler y de la nueva música. "Adorno maintains that Debussy's music is essentially undialectical in its relation to its material. The material is seen as a highly refined extension of what he calls the 'culinary' aspects of the bourgeois art music tradition, and of nineteenth-century salon music» y de «Zur gesellschaftlichen Lage der Musik», en el que, a su juicio, "Adorno's claim, that the undialectical character of Debussy's music - and indeed of French music as whole at this period - can be explained ultimately by the fact that France might not have as industrially advanced as Germany and therefore that 'alienation' was not experienced so acutely». En términos de Paddison, para Adorno, "Debussy's music [...] avoids the contradictory character of its musical material and does not take it into its 'law of form'» (M Paddison, Adorno's Aesthetics of Music, Cambridge, Cambridge University Press, 1998, pp. 257-258). Justamente, este rechazo a seguir las leyes de la forma será lo que le hará reconsiderar a Debussy para su concepto de informal. Este sería el giro que Paddison no incluye en su texto y que, a mi juicio, reconfigura la concepción de la música de Adorno de forma retrospectiva.

${ }^{34}$ Vt 205/3 «Debussy», del 28 de febrero de 1963.

${ }_{35}$ No obstante, Adorno considera que es posible hablar de una suerte de continuum —crítico- entre lo motívico-temático de la tradición y Erwartung, solo que habría que 
que trabajan a partir de mediados de 1950 comienza a "ser indiferente" $\mathrm{o}$, al menos, a configurarse desde otro lugar, la íntima relación con lo temporal, como la que se articulaba en el desarrollo variativo y la transición mínima bergiana. Su interpretación se dirige en trazar cómo "la integración de la planificación total" o el serialismo y su supuesto opuesto, "la atomización en sonidos", en la electrónica y el azar, son capaces de evitar que la espacialización de lo temporal caiga, de nuevo (como en Kant), en la conversión del tiempo en algo puro "que llenar". El reto que abre la temporalidad sería cómo pensarla como algo no dado, algo a construir cada vez y que, por ende, ponga en jaque los modelos geométricos que preforman la experiencia temporal. Es decir, a Adorno le interesa cómo se garantiza desde estas prácticas compositivas el mantenimiento de la no-identidad entre espacio y tiempo y la no reducción del elemento cualitativo de ambos a algo cuantitativo. A colación de este problema, en Negative Dialektik Adorno atestigua que la cosa ya no es un "ente completo" [schlechterdings Seiendes], sino que la cosa es «relacional» [Dinge als Verhältnisse]. Es decir, la filosofía (y la sociología) deberían renunciar a seguir tratando de captar un "ente completo" (sea este dinámico, estático o una unión de ambas) y pensarlo desde sus relaciones. Lo que está proponiendo, entonces, es una relación no violenta (o de no dominio) entre lo estático (o espacial) y lo dinámico (o temporal).

No hay posibilidad de modificar la relación sociopolítica sin modificar la temporalidad. Según Benjamin, en las relaciones temporales, el núcleo de la concepción política se esconde en cada período. Como explica en su tesis XV Sobre el concepto de historia, cualquier proceso con intención revolucionaria reestructura el tiempo y, sobre todo, trata de romper con el tiempo "homogéneo y vacío". Es una evidencia en algunos casos, como por ejemplo cómo gracias a la organización de los horarios del tren, fue posible organizar en consecuencia el horario del trabajo. Quién controla el tiempo, controla el espacio. Sin embargo, las formas geométricas se aplican sistemáticamente al tiempo: líneas, círculos o espirales. En otras palabras, las construcciones espaciales (geométricas) dominan la articulación del tiempo. ¿Cómo es posible esta modificación si las metáforas visuales se aplican constantemente para comprender el tiempo? Es decir: ¿es posible concebir el tiempo a partir de su caracterización no visual? La cuestión aquí, por tanto,

considerar tal elemento desde un marco diferente del de la variación o de la repetición (o principio de identidad temático). (Véase T. W. Adorno, Kranichsteiner Vorlesungen, Berlin, Surhkamp, 2014, pp. 516-17). 
sería qué tiempo debe atravesar el concepto de verdad que no lo llene con una estructura tradicional. Un tiempo lineal, el continuum, nos hace albergar la promesa, como en el mesiánico y la parusía, de que la verdad llegará. El tiempo circular, por su parte, se convierte en tautológico al prescindir de la linealidad. El problema, quizá, es la aplicación de una "imagen espacial” a la comprensión del tiempo. Esto tiene que ver, según explica Agamben, a que «la mente humana capta la experiencia del tiempo pero no posee una representación de ella», y por lo tanto, "necesariamente el tiempo es representado mediante imágenes espaciales» ${ }^{36}$. Por eso, continúa, en la antigua Grecia,

originalmente histôr es el testigo ocular, aquel que ha visto. La supremacía griega de la vista se confirma entonces una vez más. La determinación del ser auténtico como "presencia ante la mirada" excluye una experiencia de la historia, que es aquello que siempre está allá sin estar nunca como tal ante los ojos ${ }^{37}$.

El tiempo estructurado desde una imagen espacial impide una relación cualitativamente diferente con el tiempo. Lo espacial en el tiempo, sin embargo, permite una estructuración lógica del mismo que permita su dominio. Mi propuesta es que Adorno replantea esta estructuración lógica desde la reflexión sobre el tiempo en la música, algo que le permitiría pensar el tiempo sin la imposición de tal "imagen espacial” o, al menos, no reduciéndola a ella. La crítica a la lógica surge, en Adorno, desde la crítica a la causalidad, que trataré de trazar brevemente. En cada acción comienza, de alguna forma, una nueva cadena causal [Kausalkette]. Esto es, para Adorno, el carácter inteligible [intelligibles Charakter] de la acción y al mismo tiempo, tal y como describe en Dialéctica de la ilustración, también su principio cientifista. Sin embargo, parece que en las decisiones de los sujetos hay algo más que esa causalidad, algo que la supera, difícil de determinar. Es "lo añadido" [das Hinzutretende]: lo que quiere modificar el curso lógico de la causa-efecto ${ }^{38}$. Según Adorno, un sujeto se siente libre cuando «su acción se aparece como idéntica a él como sujeto ${ }^{39}$. Sin embargo, no hay un momento tal en que el sujeto sea idéntico de una vez para siempre a sí mismo. Lo no idéntico sería eso que no encaja exactamente en la cadena causal y que

${ }^{36}$ G. Agamben. Ensayo sobre la destrucción de la experiencia, traducción S. Mattoni, Buenos Aires, Adriana Hidalgo, 2007, p. 132.

${ }^{37}$ Ibidem, p. 136.

${ }_{38}$ T. W. Adorno, Zur Lehre von der Geschichte und der Freiheit, en Nachgelassene Schriften IV, 13, Frankfurt a. M., Suhrkamp, 2001, pp. 317-318.

39 "Nur soweit weiß das Subjekt sich als frei, wie ihm seine Handlung als identisch mit ihm qua Subjekt erscheint» (Ibidem, 320). 
permitiría romper con el oxímoron kantiano de la "causalidad por medio de la libertad", que implica la aceptación e internalización de la legalidad (impuesta por la razón sobre la cosa) como máxima libertad. Asimismo, Adorno rechaza la relación causal que busca encontrar una causa última de la que derive todo lo demás. Para él, tal causa es solo un momento mediado por sus efectos.

La estructura de causalidad implicaría la relación entre causa-efecto dentro de una construcción del tiempo en la que la intención motiva un efecto específico en lo real y, por tanto, habría que retrotraerse a ella para comprenderla. Adorno trata de eliminar la fuerza de la sucesión del pensamiento y achaca a Kant la inclusión de la causalidad en el sujeto trascendental (como categoría a priori del entendimiento, que preordena la experiencia), algo que impediría otras formas de pensamiento basados en otras estructuras temporales y, sobre todo, el ejercicio crítico con el establecimiento de cadenas de pensamientos. G. Ligeti da algunas claves para comprender el alcance de la espacialidad del sonido para el proyecto filosófico adorniano (aunque el propio Adorno no lo tuvo en cuenta) en su análisis de su obra Atmosphères, la cual fue muy relevante y valorada por el propio Adorno. Se trata de encontrar ahí el núcleo de la crítica a la causalidad. Según él, en su obra Atmosphères, donde trabaja la ruptura con el modelo estructural de composición - algo que convergería con la crítica de Metzger a Adorno sobre su concepción del componer basado en "Haupt-" y "Nebensatz"no se puede hablar de una construcción "motívico-temática", es decir, no habría "acontecimientos" [Ereignisse], sino "estados" [Zustände]. El acontecimiento implica un cierto modelo de sucesión; mientras que el estado, sin embargo, una especie de mirilla que se abre para contemplar cierta situación del material musical en un momento concreto. Tales estados «se disuelven unos a otros o se convierten de forma imperceptible unos en otros, sin que aparezcan contextos causales dentro del proceso de la forma» ${ }^{40}$. Según Adorno, en esta obra se rompe con la mayoría de los parámetros considerados fundamentales para la música y, su forma, radicalmente "se construye a sí misma desde el color" [von der Farbe selbst gebildet $]^{41}$. Sin embargo, no le extrae toda su radicalidad para pensar, a partir de tal trabajo sobre "tejidos" [Gewebe], en términos de Ligeti, es decir, para reflexionar desde la música el problema de la causalidad y, con él, el del encadenamiento en el pensamiento. Confrontarse a esta música le lleva, en sus últimos años, a

${ }^{40}$ G. Ligeti, Gesammelte Schriften, Basel-Mainz, Schott, 2007, p. 181.

${ }^{41}$ T. W. Adorno, Kranichsteiner Vorlesungen, Berlin, Surhkamp, 2014, p. 511. 
afirmar que el "desarrollo musical” es "en realidad, en gran parte, un desarrollo de la negación [...] que contiene lo negado en sí mismo" ${ }^{42}$. Es decir: ya no defiende el modelo de expectativa-espera que, para él, articulaba el tiempo en la música tradicional, sino que asume la temporalidad desde su propia negación. Adorno se da cuenta al final de su vida de que la organización del material, sea siguiendo sus exigencias o no, implica hacerle violencia de alguna forma al imponerle un modelo sintético con otros materiales. Esto implica, por un lado, una vuelta a la subjetividad enfática que aparecería en tal proceso de organización y, por otro, un concepto de material que tiene que renunciar a algo de lo que es para poder participar de la síntesis artística. Para eso, según indica a Adorno, en realidad a los materiales se los arranca de cierta organización en lo real (una que era "heterónoma") para ser parte de otra, la artística, que, en tanto los organiza siguiendo sus exigencias, se volvería "autónoma" con respecto a ellos. Esta tensión sería huella de la construcción, pero también de expresión: lo que se expresa es precisamente este proceso de desgarro con respecto a lo real y reincorporación en una nueva articulación. La cuestión clave se encuentra en pensar si es posible una organización del material que no responda a la vieja creencia que reza que lo real es idéntico a la estructura del pensamiento, sino encontrar en lo real claves para pensar formas cualitativamente distintas, no dominadoras, del pensar. Volveremos a este tema al final del texto.

\section{Prohibición de las imágenes: hacia la espacialización}

Adorno, desde su trabajo sobre Kierkegaard hasta Dialéctica negativa, va a trazar una posición antiiconoclasta. La prohibición de las imágenes, a su juicio, rescata algo fundamental que se ha perdido en la herida del lenguaje: «el vínculo entre nombre y ser» ${ }^{43}$. La prohibición de las imágenes tiene como tema principal la posibilidad o no de la "inseparabilidad de lo espiritual y lo corporal". Es decir, "no hay... nada "espiritual" que no se funde de algún modo en la percepción corpórea ni exija a su vez su realización corpórea [leibhaft]» ${ }^{44}$. Esto nos lleva a un tema clásico de la estética: cómo la forma es capaz o no de captar el contenido. Para Hegel justo en este asunto se encuentra la superioridad de la belleza estética frente a la natural, pues ésta es amorfa: el hombre la mejora. La tradición judeocristiana, sin

${ }^{42}$ Ibidem, p. 460.

${ }^{43}$ T. W. Adorno, Gesammelte Werke, Volumen 3, Frankfurt a. M., Suhrkamp, 1976, p. 40.

${ }^{44}$ T. W. Adorno, Gesammelte Werke, Volumen 13, Frankfurt a. M., Suhrkamp, 1976, p. 277. 
embargo, el intento de mejora de lo dado por el hombre es una arrogancia de los seres humanos de intentar emular la potencia divina. Así lo expresa San Pablo en su discurso de Atenas (Hechos 17,29): «Si somos estirpe de Dios, no podemos pensar que la divinidad se parezca a imágenes de oro o de plata o de piedra, esculpidas por la destreza y la fantasía de un hombre».

En su «Sakrales Fragment: Über Schoenbergs Moses und Aron» ${ }^{45}$, Adorno plantea la posibilidad de pensar la música sin imágenes, sin la representación a través de la revisión de la prohibición de las imágenes judía. La música ha adquirido un carácter de imagen «poco a poco, intermitentemente y siempre con precariedad ${ }^{46}$. Para él, la música, en este aspecto es como los rituales o la "acción cúltica": para "desvelar algo en el lenguaje verdadero", debe someterse, obedecer a "una legalidad que se consuma por encima del espíritu de sus participantes" ${ }^{47}$. Es decir, para desvelar, por ejemplo, el poder de los dioses sobre la naturaleza, los miembros del colectivo deben bailar de una forma concreta. O, como en Stravinsky, para glorificar la naturaleza y el inicio de la primavera, una joven debe morir bailando por el bien de su comunidad (esto es, un concepto abstracto). La música perdió paulatinamente lo específico de lo sonoro (no tener imagen) y "aprendió a imitar”. No sólo por el intento de traspasar la representación figurativa a lo sonoro, como en las tormentas de Vivaldi o en los pajarillos de Mahler, sino que llegó a querer renunciar a eso distinto que porta con respecto a la imagen. Así, la música se hizo cargo de «la ingrata tarea de [...] ser la imagen de lo carente de imagen ${ }^{48}$. En esta línea trata Adorno de explicar cómo la música, en realidad, ha llegado a ser — a su pesar- un arte de la literalidad.

Adorno intenta, aunque de forma fragmentaria, trabajar la relación entre la representación y la música. Rechaza la «mera banalización de las imágenes que surgen de una concepción meramente representativa de la música: como cuando la barcarola de Los Cuentos de Hoffmann anima al director a mostrar el abrazo de una pareja de enamorados en un escenario veneciano ${ }^{49}$. Pero no se trata, para él, de arrebatar la ingenuidad, sino de preguntarse no sólo lo que la música representa, sino cómo y si puede representar algo. Ya no es solamente que la música pueda o no "convertirse" en imagen, sino que hay cierta abstracción de cómo "sonarían” ciertas imágenes

${ }^{45}$ T. W. Adorno, Gesammelte Werke, Volumen 16, Frankfurt a. M., Suhrkamp, 1976, pp. 454-475.

${ }^{46}$ T. W. Adorno, Gesammelte Werke, Volumen 10.1, Frankfurt a. M., Suhrkamp, 1976, p. 447.

${ }^{47}$ T. W. Adorno, Gesammelte Werke, Volumen 16, Frankfurt a. M., Suhrkamp, 1976, p. 457.

${ }^{48}$ Ibidem, p. 458.

${ }^{49}$ T. W. Adorno, Gesammelte Werke, Volumen 15, Frankfurt a. M., Suhrkamp, 1976, p. 67. 
que se adscriben acríticamente a lo sonoro. Un tremolo en los bajos, en un réquiem como el de Mozart (pensemos en el "Dies Irae"), "representa" un terremoto aunque ningún terremoto sonará nunca así. Pero, al mismo tiempo, la representación sonora-visual de ese terremoto se junta con la representación sonoro-visual del nerviosismo y el terror del que se va a morir. Es decir, en este ejemplo hay una traducción de un contenido subjetivo en un material supuestamente natural. En el análisis de la representación, Adorno piensa en un paralelismo entre la "función mágica" de la música y su relación con el soporte visual, como en el cine. Para él, en el origen del cine «la música se introdujo como un antídoto contra la imagen». Ésta, aún hacía de sus personajes una suerte de espíritus, personajes parecidos pero ajenos a lo real que, «vivían pero al mismo tiempo no vivían», por lo que «la música no pretendía tanto otorgarles la vida que les faltaba [...] como apaciguar el miedo y calmar el shock» ${ }^{50}$, algo similar a lo que ocurre con el muzak, la música de las salas de espera o de los aviones y que explícitamente sucede en el género del musical, donde cantar adquiere una función similar a la de la ópera: la reflexión sobre la acción. Igual que en las películas de la primera mitad del siglo XX, donde el blanco y negro se utilizaba para aquellas que prometían una ficción cercana a la realidad y el color para lo fantástico, la explotación de lo musical adquiere un peso similar al color, como un paréntesis en la acción. La música, por tanto, enmarca la imagen, anticipa los sustos en las películas de miedo, apoya las emociones de ternura en las de amor o multiplica la hilaridad en las de humor. Adorno traza la prehistoria de estos recursos en esta conversión de lo sonoro en imagen donde, lo que ha sucedido es que lo sonoro había quedado recluido a lo que su conversión en imagen le permitía. De este modo, al mismo tiempo, se pregunta si es posible una música emancipada de las exigencias de la imagen.

Prueba de que el problema de la espacialización de lo sonoro le preocupó durante sus últimos años sin alcanzar una respuesta suficiente es que uno de los textos básicos sobre el asunto, «Über einige Relationen zwischen Musik und Malerei» ${ }^{51}$ fue redactado en 1963 y retocado en 1965 y 1968, sólo un año antes de su muerte y de que publicase un texto fundamental, «Die Kunst und die Künste» ${ }^{52}$. Adorno se da cuenta, como hemos señalado, de que el tiempo no fluye meramente, sino que «se coagula como algo autónomamente perseverante, como objeto, como cosa. Por eso se llama forma musical a su ordenación temporal. El término "forma" remite la articulación

${ }^{50}$ Ibidem, p. 75.

${ }^{51}$ T. W. Adorno, Gesammelte Werke, Volumen 16, Frankfurt a. M., Suhrkamp, 1976.

52 T. W. Adorno, Gesammelte Werke, Volumen 10.1, Frankfurt a. M., Suhrkamp, 1976. 
temporal de la música al ideal de su espacialización» ${ }^{53}$. Es decir, Adorno asevera que ya en el mismo concepto de "forma" se encuentra un momento espacial: que no es posible pensar lo espacial sin su fijación dimensional, en el espacio. Pero, para Adorno, también sucede al revés el arte espacial, la pintura, "en cuanto elaboración del espacio", lo "dinamiza" y lo "niega" (a là Hegel). A lo que se refiere es que en un cuadro se detiene en el espacio lo simultáneo con intención de ser eterno. En otros términos, se trataría de otra forma de fijación espacial de lo temporal. Por tanto, vemos cómo Adorno pasa de la tematización del tiempo qua tiempo en sus textos sobre Beethoven y Berg al tiempo qua dialécticamente mediado por el espacio. Dicho con Wellmer,

el descubrimiento del espacio en la música corresponde con el descubrimiento de lo temporal de la imagen, sin lo cual la música perdería su forma temporal y las imágenes su espacialidad: el tiempo y el espacio se vuelven visiblemente lo constitutivo de todo arte en tanto tiempo-espacio y espacio-tiempo ${ }^{54}$.

En su manuscrito de 1944 Composition for Film (publicado en 1947)/ Komposition für den Film publicado en 1949) $)^{55}$ apunta los primeros elementos sobre la relación entre imagen y música, primero en un sentido específico (en el cine) y, después, en sentido general; esto es, cómo es posible y de qué forma se articula la relación entre la imagen y el sonido. Para Adorno, hay una diferencia fundamental entre la imagen y el sonido que tiene consecuencias para su relación con la realidad. Para él, mientras que «la música, por mucho que la determine su propia forma compositiva, nunca se define teniendo en cuenta algún objeto que le sea externo o al que se refiera por imitación o expresión». Sin embargo, las imágenes, "incluso las abstractas", no pueden estar "completamente emancipadas de su condición de objeto» ${ }^{56}$. Es decir, Adorno considera, tal como explicita un poco más adelante en este texto, que la música se relaciona "sustancialmente y en primer lugar" con la interioridad, mientras que lo visual «tiene que soportar la carga de lo objetivo indisoluble ${ }^{57}$. De algún modo, lo que está evidenciando es algo parecido a que la música se relacionaría con lo interior y lo visual con lo exterior. Para él, en esta época, se da aún un "extrañamiento de los

${ }^{53}$ T. W. Adorno, Gesammelte Werke, Volumen 16, Frankfurt a. M., Suhrkamp, 1976, p. 628.

${ }^{54}$ A. Wellmer, Versuch über Musik und Sprache, München, Carl Hanser, 2009, p. 315.

${ }^{55}$ Las diferencias entre los años de publicación con respecto al manuscrito original son remarcadas porque se observan algunas diferencias entre ellos. La que está en las obras completas es la edición que hizo Adorno del texto en 1969.

${ }^{56}$ T. W. Adorno, Gesammelte Werke, Volumen 15, Frankfurt a. M., Suhrkamp, 1976, p. 72.

${ }^{57}$ Ibidem. 
medios artísticos" y, específicamente, pone como punto de mira de este extrañamiento tres "medios", a saber, la música, la imagen y la palabra.

Posteriormente, sin embargo, Adorno se da cuenta de que hay una relación entre artes que no se encuentra en la tradición, que él llama "entrelazamiento". No se trata de la identificación entre una imagen concreta y un sonido. Adorno rechaza el para qué de tal identificación, pues el entrelazamiento no consiste en la repetición lo que un medio artístico ya ha generado por sí mismo, sino en el surgimiento de una nueva manera de aparición de ese medio por la influencia de otro distinto. En su tematización, considera que el entrelazamiento parte de dos lugares: primero, del rechazo de la "raza pura y la difamación de los híbridos" del nacionalsocialismo y otros racismos que parecería que obedece a un principio que ha existido en la estética desde su origen; y que nos lleva al segundo punto, a saber, la división entre artes. Ésta, a su juicio, ha resultado forzada no sólo entre géneros, sino también dentro de los propios géneros y artes. Para él, es un "tabú civilizatorio" la tendencia a la clasificación en la que también cae el arte. Adorno insiste en varios lugares en que la obra de arte no podría ser tal sin un elemento heterogéneo con respecto a ella misma y también al sujeto creador. Operan, al mismo tiempo, el peso del género, de los materiales y la subjetividad. Mientras que hasta esta última década, para Adorno la relación entre forma y contenido es dialéctica dentro de cada una de las obras de arte, en estos últimos años piensa en si esta relación se da también entre formas entre las artes, es decir, también fuera de ellas. Y, segundo, el entrelazamiento pondría en duda que haya una sola forma específica en el proceder artístico. Señala que «lo mismo a lo que las artes se refieren como su "qué" se convierte en otra cosa según "cómo" se refieran a ello. El contenido de las artes es la relación del "qué" [Was] con el "cómo" [Wie]»" Por eso, aunque las baladas de Brahms «recuerdan a las armaduras de los caballeros y a los trovadores [...] [1] a suerte de Brahms fue que sus baladas se convirtieron en música, no en poemas ${ }^{59}$. No se trata, por tanto, de que Brahms compusiera música y no poemas, sino cómo aparece lo visual sedimentado en lo sonoro y cómo solo desde tal exploración de lo visual en lo sonoro se puede comprender la construcción sonora brahmsiana.

En su reflexión sobre la relación entre música y pintura, Adorno habla de écriture: lo temporal de la pintura no lo sitúa en lo que "aparece pintado", sino — a là Derrida— “en lo pintado mismo”. En este marco, cabría pensar

${ }^{58}$ T. W. Adorno, Gesammelte Werke, Volumen 10.1, Frankfurt a. M., Suhrkamp, 1976, p. 442.

${ }^{59}$ Ibidem. 
a Adorno desde Rancière y su concepto de "pensatividad". Según Rancière, «la imagen era... dos cosas: la representación directa de un pensamiento o de un sentimiento; y la figura poética que sustituye a una expresión por otra para aumentar su potencia» ${ }^{60}$. La pensatividad cifra el desvanecimiento de esta capacidad de representar "directamente" o de ser "sustitutas" de un contenido a favor de formas de relación que no crean una relación directa y heterónoma entre imagen/sonido y objeto a representar. Había ciertas convenciones que permitían, en la imagen, identificar un «término "propio" y el término "figurado", por ejemplo, entre un águila y la majestad o entre un león y el coraje» ${ }^{61}$. Según Rancière, la pensatividad hace convivir varios regímenes de expresión. El ejemplo lo toma de Madame Bovary, donde en la narración irrumpen "pequeñas escenas visuales", que hacen que la narración se abra, señale hacia otros mundos posibles paralelos. Eso, para él, hace «contrarias la lógica de la acción. Por una parte, prolonga la acción que se detenía. Pero, por otra parte, pone en suspenso toda conclusión ${ }^{62}$. Si se rompe no solamente, como propone Rancière, con el régimen de representación a favor del estético, sino también, como sugiere Adorno, con lo que en la configuración de las obras legitimaba tal vinculación entre lo propio y lo figurado, es cuando aparece ese giro hacia la "écriture".

La "narración" es un asunto heredado en lo sonoro de lo visual, que organiza sus eventos en un marco temporal específico. Sin embargo, en la música se combinan diferentes modalidades del tiempo. Adorno rechaza el tiempo como elemento "disponible" y como "posesión". Si hay un tiempo que no nos pertenece nunca es el musical, algo que demuestran obras como Die Soldaten de Bernd Alois Zimmermann. Según Rancière, el paso del régimen representativo al estético es la ruptura con la narración, más o menos lineal. Hay una "suspensión" de la temporalidad mediante la inclusión de otras temporalidades en las que no necesariamente pasa algo, sino que se conjugan formas de expresión:

cada uno de los momentos amorosos que puntúa Madame Bovary está marcado, en efecto, por un cuadro, una pequeña escena visual: una gota de nueve fundida que cae sobre la sombrilla de Emma, un insecto sobre la hoja de un nenúfar, [...]. Son cuadros, pasivas impresiones fugitivas que detonan los acontecimientos amorosos. Es como si la pintura viniera a tomar el lugar del encadenamiento narrativo del texto ${ }^{63}$.

${ }^{60} \mathrm{~J}$. Rancière, El espectador emancipado, traducción A. Dillon, Buenos Aires, Manantial, 2010, p. 117.

${ }^{61}$ Ibidem, p. 118.

${ }^{62}$ Ibidem, p. 119.

${ }^{63} \mathrm{~J}$. Rancière, «La imagen pensativa», en El espectador emancipado. Buenos Aires, Manantial, 2010, pp. 119-120. 
¿Qué y cómo se detona en lo sonoro? Tal convivencia de articulaciones temporales existe en la música desde el desarrollo de la polifonía, como el propio Adorno tenía de alguna forma en cuenta. Mi lectura apunta a enfatizar justamente lo espacial en lo sonoro en relación a la objetualidad, como explicaré al final del texto. Por el momento, baste señalar que hay momentos en la historia de la música que evidencian un trabajo más cercano entre lo espacial y lo temporal, como el desarrollo del "espectrograma", la representación microscópica del sonido que, en cierto modo al igual que la electrónica, permitía operar a nivel fragmentario y mínimo con el sonido, algo que incide al mismo tiempo en el trabajo sobre lo sonoro expuesto, como nunca, en bruto y su conversión en material. Esa exploración micrológica de lo temporal implica una dominación mayor y desde dentro, algo que no había sucedido previamente en la música y que convertía su acercamiento a lo temporal como algo externo. Pero, al mismo tiempo, Adorno aprende de Stockhausen que «las obras electrónicas que no están escritas en su material, sino que son "realizadas" de inmediato en su material, podrían extinguirse con éste» y, por tanto, "es un arte dispuesto a degradarse», donde la escritura es marca de tal degradación y no huella imborrable de la obra en la historia del arte. La música electrónica abre el problema de que el núcleo de la música ya no está en su gramática o en "las vocales de la música", sino en que tal material degradado pone en tela de juicio el material sonoro usado hasta entonces. Siguiendo a Stockhausen, la clave se encontraría en que lo imaginado a nivel sonoro, que la estructura física de los instrumentos tradicionales no permitía o, al menos, limitaba, es posible mediante la electrónica ${ }^{65}$.

Hay un aspecto que Adorno sólo nombra de pasada y que es fundamental para comprender las derivas compositivas en los últimos años, tanto en música, como en instalación sonora y arte sonoro. Se trata de la externalización del espacio con respecto a lo sonoro, es decir, que lo espacial no sea sólo un elemento en el que la música se objetualiza o en el que se fija, o el lugar de confrontación de lo simultáneo (tal y como define Adorno lo espacial) frente a lo no simultáneo (lo específicamente temporal); sino que lo sonoro configure el espacio en el que suena mientras suena. Lo apunta brevemente: «la orquesta de Bruckner no sería lo que desde un punto de vista puramente musical es si le faltara la cualidad de lo envolvente, del bosque

${ }^{64}$ T. W. Adorno, Gesammelte Werke, Volumen 7, Frankfurt a. M., Suhrkamp, 1976, p. 265.

${ }_{65}$ K. Stockhausen, "Elektronische und instrumentale Musik», en Texte zur und Instrumentalen Musik, Köln, DuMont, Schauberg, 1963, p. 98. 
sonoro que se aboveda en torno al oyente ${ }^{66}$. La externalización del espacio en música adquiere dos derivas. Por un lado, la distribución de la música en el espacio, que puede generarlo, como es evidente con el trabajo sonoro en la película Nostalghia de Tarkovsky; y, por otro, la materialidad de la fijación de la música en un soporte distinto al escrito, la posibilidad de ser reproducida infinitamente, en su conversión en un "archivo disponible", ${ }^{67}$ en lo que eso modifica en su relación con la memoria.

En cualquier caso, mi interpretación de la inclusión del espacio en lo sonoro - y viceversa- en Adorno se enmarca dentro de ese contexto tematizado por Rancière de desplazamiento de lo narrativo y representativo, pero añade la reflexión sobre el rol de lo objetual como lo figurativo. En Adorno, se produce una ruptura entre signo y significado, es decir, al eliminar la narración y la representación como elementos fundantes, en los que lo artístico se volvía un mero medio, un elemento meramente derivado, desaparece para Adorno ese "yo sintetizador" y, sobre todo, aparece un "lenguaje no subjetivo" - es decir, un lenguaje que no tiene como prioridad la duplicación del mundo interior de un sujeto- ${ }^{68}$. La unión entre lo espacial y el sonido es marca de lo que Adorno considera el verdadero cambio en el concepto de construcción y también la marca de la convergencia entre música y pintura: la confrontación "con el material desnudo con el que trabajan, sin el estrato intermedio de un objeto o de un idioma: unidad no mediante un tercero exterior a la cosa» ${ }^{69}$.

\section{Conclusiones preliminares}

Si bien en el concepto de verdad que recorre toda su obra — también aún en Ästhetische Theorie - se refiere a que las obras de arte sólo dicen si no dicen y que ese decir es dado por la filosofía, de tal modo que arte y filosofía convergen en el intento de nombrar eso que no se pudo decir; en este texto sobre Beckett Adorno señala que es una obra sobre la que ya no

persigue la quimera de expresar su sentido por mediación de la filosofía. Entenderla no puede significar otra cosa que comprender su ininteligibilidad, reconstruir concretamente la coherencia de sentido de lo que carece de él. Escindido, el pensamiento ya

${ }^{66}$ T. W. Adorno, Gesammelte Werke, Volumen 16, Frankfurt a. M., Suhrkamp, 1976, p. 632.

${ }^{67}$ J. Rancière, Metamorphoses of the muses, en C. Kelly (ed.), Sound, Massachussets, MIT Press, 2011, p. 128.

${ }^{68}$ T. W. Adorno, Gesammelte Werke, Volumen 16, Frankfurt a. M., Suhrkamp, 1976, p. 635 .

${ }^{69}$ Ibidem, p. 640. 
no pretende, como antes la idea, ser el sentido de la obra misma; una trascendencia que sería engendrada y garantizada por su inmanencia ${ }^{70}$.

Es decir, la filosofía ya no hace decir nada al arte, ya no le exige que haga algo que no puede hacer, sino que trata de comprender precisamente ese no decir. Pero no se ttrata de una cuestión meramente lingüística, sino de postura ante y de la objetividad de la obra. Adorno se da cuenta que, de forma velada, este intento de la filosofía de ayudar a las obras de arte a decir lo que no pueden decir implica en cierto modo la constatación de una filosofía y de un concepto de arte que no se hace cargo de aquello «en lo que el espíritu mismo se ha convertido, residuos reificados de la cultura ${ }^{71}$. No está, en su base, la de tratar de que conocimiento y objeto converjan, sino precisamente mostrar las heridas de la divergencia. Si, como el propio Adorno señala, la dialéctica es "la doctrina de la contradicción" en la medida en que critica la "logicidad simple del mundo", parece explicita la divergencia entre mundo y pensar pero apuesta por la posibilidad de que tal convergencia en la que «el pensamiento debe intentar comprender lo que él mismo no es» ${ }^{72}$. Considero que, a diferencia de posturas de corte habermasiano, Adorno no estaba tratando de depurar la razón o de rearticularla, sino de pensar sus presupuestos. Quizá dos de los más importantes presupuestos de la razón son el espacio y el tiempo, que son comprendidos como categorías que dirigen a legitimar ciertos modelos de representación y estructuración lógica de los objetos del conocimiento, algo que implica un principio de dominación en el conocer.

Mi lectura de Adorno incide en esa radical apuesta por un modelo filosófico que sea capaz de aproximar, sin dominarlo, "lo que él mismo no es". Para ello, debe romper con categorías que preorganizan la experiencia: de ahí que Adorno abogue por una "experiencia no reglamentada". Lo sonoro puede aportar la radical crítica a la representación, que ha quedado desbordada por los hechos históricos, cuando «desde Auschwitz, temer la muerte significa temer algo peor que la muerte», es decir, cuando la representación puede ser incluso peor que aquello que tenía que atrapar de la realidad y que, por tanto, ya ni siquiera encuentra en ella. El arte no es "representación" ni de algo concreto (por ejemplo, la silla o los zapatos de Van Gogh) ni de algo espiritual en tanto abstracto (la libertad, el monarca). El ir más allá del arte no consiste en "superar" un estado de cosas de la realidad.

${ }^{70}$ T. W. Adorno, Gesammelte Werke, Volumen 11, Frankfurt a. M., Suhrkamp, 1976, p. 283.

71 Ibidem.

72 T. W. Adorno, Einführung in die Dialektik, en Nachgelassene Schriften, IV, 2, Berlin, Suhrkamp, 2010, p. 104. 
«No es una copia, no es una reproducción del "estado antagonista" " que caracteriza la realidad, sino que es un exceso: «el arte se ha convertido [versetzen] en lo otro de ese estado ${ }^{73}$. El arte da cuenta de que el conocimiento, para Adorno, no es algo que se pueda "poseer". El espejo del arte en el que la realidad se mira no la ayuda a conocerla mejor en tanto lo que es, sino en tanto lo que es sin fantasmagoría, en su deformación. En esto, el arte coincide radicalmente con lo que Adorno considera que es la aportación materialista al conocimiento: le presenta "su espejo deformador, porque en tal espejo aparece precisamente lo que el conocimiento olvida» ${ }^{74}$. Por tanto, el contenido de verdad del arte da "algo que no existe" no en tanto utopía (como un lugar fuera que alcanzar), sino en tanto irrepresentable -que no consigue tener representación en el marco del conocimiento en el que se articula nuestro modelo del conocimiento: «lo que el arte busca es eso otro [...] [que] no es unidad y concepto, sino algo plural [...], lo no hecho» ${ }^{75}$. En este sentido, el arte no es ni tiene objeto, sino radicalmente no-objetual [“Ungegenständlich”]. Eso es lo que, a mi juicio, la teoría del conocimiento tiene aún que aprender del arte.

\section{Bibliografía}

Adorno, Theodor W. Kranichsteiner Vorlesungen, en Nachgelassene Schriften IV, 17, Berlin, Suhrkamp, 2014.

Adorno, Theodor W. Einführung in die Dialektik, en Nachgelassene Schriften, IV, 2, Berlin, Suhrkamp, 2010,

Adorno, Theodor W. Zu einer Theorie der musikalischen Reproduktion, Frankfurt a. M., Suhrkamp, 2005.

Adorno, Theodor W. Zur Lehre von der Geschichte und der Freiheit, en Nachgelassene Schriften IV, 13, Frankfurt a. M., Suhrkamp, 2001.

Adorno, Theodor W. Gesammelte Werke, Frankfurt a. M., Suhrkamp, 1976.

Agamben, Girogio. Infancia e historia. Ensayo sobre la destrucción de la experiencia, traducción S. Mattoni, Buenos Aires: Adriana Hidalgo, 2007.

Benjamin, Walter. «Trauerspiel y tragedia», en Obras completas, II-1, traducción Jorge Navarro Pérez, Madrid, Abada, 2007.

73 T. W. Adorno, Gesammelte Werke, Volumen 7, Frankfurt a. M., Suhrkamp, 1976, p. 386.

${ }^{74}$ T. W. Adorno, Terminología filosófica, Madrid, Taurus, 1991, p. 132.

75 T. W. Adorno, Gesammelte Werke, Volumen 7, Frankfurt a. M., Suhrkamp, 1976, p. 199. 
Bidon-Chanal, Sol. "Música envejecida y retorno a la libertad. Las críticas a la Escuela de Darmstadt de T. W. Adorno y su propuesta de una “musique informelle" » en Cadernos de Filosofia Alemã, 20; n. 2 (2015), pp. 201-217.

Boissière, Anne. La pensée musicale de T.W. Adorno : l'épique et le temps, Paris, Printemps, 2010.

Borio, Gianmario y Danuser, Hermann. Im Zenit der Moderne. Die Internationalen Ferienkurse für neuen Musik Darmstadt 1946-1966, Freiburg im Breisgau, Rombach, 1997.

Borio, Gianmario. «Die Positionen Adornos zur musikalischen Avantgarde zwischen 1954 und 1966», en Sonntag, Brunhilde (ed), Adorno in seinen musikalischen Schriften, Regensburg, Gustav Bosse, 1987.

Campbell, Edward. Boulez, Music and Philosophy, Cambridge, Cambridge University Press, 2010.

Kreis, Guido. «Kritik der avantgardistischen Vernunft. Kants Grundlegung des Kunstwers und Adornos Kriterien der neuen Musik», en R. Klein (ed), Gesellschaft im Werk. Musikphilosophie nach Adorno, Freiburg, Karl Alber, 2015.

Ligeti, Gyorgy. Gesammelte Schriften, Basel-Mainz, Schott, 2007

Metzger, Heinz-Klaus. «Das Altern der Philosophie der neuen Musik», en Die Reihe, vol. 4 (1958), pp. 64-80.

Metzger, Heinz-Klaus. Literatur zu Noten, Frankfurt a.M., Suhrkamp, 1980.

Paddison, Max. Adorno's Aesthetics of Music, Cambridge: Cambridge University Press, 1998.

Philips, Wesley. Metaphysics and Music in Adorno and Heidegger, New York, Palgrave Macmillan, 2015. https://doi.org/10.1057/9781137487254

Rancière, Jacques. El espectador emancipado, traducción A. Dillon, Buenos Aires, Manantial, 2010.

Rancière, Metamorphoses of the muses, en C. Kelly (ed.), Sound. Massachussets: MIT Press, 2011.

Schnebel, Diether. "Der Ton macht die Musik oder: Wider die Versprachlichung», en Anschlage-Auslage. Texte zur neuen Musik, München-Wien, Hanser, 1993

Stockhausen, Karlheinz. "Elektronische und instrumentale Musik», en Texte zur und Instrumentalen Musik, Köln, DuMont, Schauberg, 1963. Wellmer, Albrecht. Versuch über Musik und Sprache, München, Carl Hanser, 2009. 